\title{
Interactions between the immune system and the ruminant conceptus
}

\author{
P. J. Hansen \\ Department of Dairy and Poultry Sciences, University of Florida, Gainesville, FL 32611-0920, \\ USA
}

\begin{abstract}
Interactions of the conceptus with the immune system can involve either anti-sperm or anti-conceptus immune responses that limit the success of pregnancy or beneficial effects of cytokines released from lymphoid cells on embryonic growth and gene expression. The immune system is functional in the uterus and therefore there is the potential for anti-conceptus immune responses. However, endometrial lymphocytes are distinct in many respects from lymphoid cells at peripheral sites; one major subpopulation expresses the $\gamma \delta \mathrm{T}$-cell receptor and may not recognize major histocompatibility antigens. There are also several control systems to limit anti-conceptus immune responses. In particular, expression of major histocompatibility antigens on the trophoblast is either absent or of limited distribution. In addition, activation of anti-conceptus immune responses leading to cytolytic responses is further limited by the presence of molecules that can inhibit lymphocyte transformation. The most well-characterized of these are prostaglandin $\mathrm{E}_{2}$ from placental and endometrial tissues, interferon- $\tau$ from the trophoblast during early pregnancy, and two endometrial proteins called the uterine milk proteins (UTMP). Progesterone plays a central role in inhibition of immune responses in actions that are mediated at least in part through endometrial secretion of UTMP. Cytokines play important roles as autocrine and paracrine regulators in many tissues including the reproductive tract. In ruminants, the best described example is interferon- $\tau$. Other cytokines found in the reproductive tract or produced by the conceptus include interleukin- $I$, leukaemia inhibitory factor, granulocyte-macrophage colony stimulating factor and interleukin-6. It is possible that the major source of cytokines in the reproductive tract is non-lymphoid cells of the endometrium and trophoblast. It is not known to what extent endometrial lymphocytes contribute to the cytokine milieu because no cytokine has been identified as a product of endometrial lymphocytes. However, there is a population of granulated lymphocytes that increase in number and granularity in the luminal epithelium of the late-pregnant ewe that is a potential source of cytokines.
\end{abstract}

\section{Introduction}

The possibility that interactions with the maternal immune system affect development and growth of the conceptus has been recognized since Sir Peter Medawar's description of the fetus in 1953 as an "antigenically-foreign body". Several mechanisms by which the fetal allograft might survive or prevent immunological attack have been delineated. They include: (I) lack of expression of histocompatibility antigens on the placenta; (2) separation of maternal and fetal systems; (3) immunosuppression at the interface between conceptus and mother; and (4) the existence of the uterus as an immunologically 
privileged site. Each of these mechanisms has been examined experimentally and, except for the last hypothesis, there is good evidence that all are operative to some degree. A second major impetus directing research in the field of reproductive immunology was provided by Thomas Wegmann's iconoclastic interpretation of the relationship between the conceptus and the maternal immune system. Wegmann (1988) argued that recognition of conceptus antigens by the maternal immune system could be beneficial to the conceptus through provision of growth-promoting cytokines at the fetal-maternal interface. This concept, called the immunotrophism theory, has resulted in a new understanding of the role of immune cytokines in the establishment and maintenance of pregnancy. It is now known that lymphocyte-mediated interactions with the conceptus are not required for pregnancy, since normal pregnancy rates can occur in mice deficient in B-and T-cells (Croy and Chapeau, 1990). However, such interactions could modify the likelihood of a successful pregnancy. In addition, macrophages may be important for pregnancy (Pollard et al., 1991), and the endometrium and placenta produce a variety of immune cytokines that may also be important for regulation of placental function.

The study of immunological relationships between the conceptus and dam of domestic animals has lagged behind studies in rodents and humans. In part, this is because reagents and laboratory procedures required to make a detailed study of domestic animal immunology are only now becoming available. More importantly, it has not been established that aberrations in conceptus-immune interactions lead to reproductive problems in domestic animals. Notwithstanding, cells and soluble products of the immune system do participate in establishment and maintenance of pregnancy. This participation includes surveillance and removal of microorganisms from the reproductive tract and could also involve anti-sperm or anti-conceptus immune responses that limit the success of pregnancy as well as beneficial effects of cytokines released from leucocytes on embryonic growth and gene expression. Possible strategies for manipulating immune responses to improve reproductive function are emerging. For example, products of activated lymphocytes can stimulate growth of cultured bovine placental cells (Low et al., 1991a) and the incidence of retained fetal membranes is related to histocompatibility between conceptus and dam (Joosten et al., 1991). Development of management schemes to enhance reproductive function of domestic animals through manipulation of immunological function will require a good knowledge of the immunological relationship between conceptus and dam in domestic animals. The purpose of this review is to detail what is known about this relationship in ruminants.

\section{Lymphocyte Populations in the Uterus}

\section{Characteristics}

The uterus is by no means an immunologically privileged site - tissue graft rejection can occur in utero (Hansen et al., 1986) and local antibody production can be induced by intrauterine immunization (Watson ef al., 1990). Functional immunological defences are probably a prerequisite to reproduction because the reproductive tract is repeatedly exposed to microorganisms as a result of breeding, parturition and other causes. The lymphocyte subpopulations in the endometrium have been best described in the sheep (Table 1). These cells are distinct in many regards from peripheral blood lymphocytes and resemble more closely the lymphocytes in the gut. Intraepithelial lymphocytes fall into three major subclasses, based on their reactivity to three differentiation antigens (Meeusen ef al., I993). The most abundant population in nonpregnant animals (about $50 \%$ of the lymphocyte population) is a cell having the phenotype $\mathrm{CD} 8{ }^{+} \mathrm{CD} 45 \mathrm{R}^{-} \gamma \delta \mathrm{T}$-cell receptor (TCR)-negative. The remainder of the intraepithelial lymphocytes are about equally represented in two classes, a CD $8{ }^{+} \mathrm{CD} 45 \mathrm{R}^{+} \gamma \delta \mathrm{TCR}^{-}$ cell, and a CD8 ${ }^{+} \mathrm{CD} 45 \mathrm{R}^{+} \gamma \delta \mathrm{TCR}^{+}$cell. None of these cells reacts strongly with the T-cell marker CD5 (Lee et al., 1988; Gogolin-Ewens et al., 1989; Meeusen et al., 1993). Similarly, expression of the CD8 marker is weak for the CD45R ${ }^{+}$lymphocytes (Meeusen et al., 1993). Moreover, expression of B-cell markers on intraepithelial lymphocytes is rare (Meussen et al., 1993).

Few lymphocytes are present in the stroma except in lymphoid follicles that contain primarily B cells (Lee et al., 1988). Other cells located in the stroma include a few $\mathrm{CD}_{4}{ }^{+}$cells ( $\mathrm{T}$ cells that recognize antigen in association with $\mathrm{MHC}$ class II molecules, classically defined as helper $\mathrm{T}$ cells) and $\mathrm{CD} 8^{+}$cells. ( $\mathrm{T}$ cells that recognize antigen in association with MHC class 1 molecules, classically defined as 
suppressor/cytotoxic T cells), as well as cells positive for MHC class II antigen that represent B cells and macrophages (Lee et al., 1988; Gogolin-Ewens et al., 1989; Gottshall and Hansen, 1992). The predominant immunoglobulin in uterine secretions, at least in cattle, is $\operatorname{IgG}$ derived from serum transudation and local synthesis (Curtain et al., 1971; Lander Chacin et al, 1990). IgA is an immunoglobulin characteristically produced by mucosal epithelia and is also present in uterine secretions (Curtain ef al., 1971; Lander Chacin et al., 1990).

\section{Regulation of numbers of endometrial lymphocytes}

There is a decline in the number of intraepithelial lymphocytes when attachment of the conceptus to the endometrium occurs. This reduction has been described as a local effect at the site of attachment, as reported at days 22-24 in sheep (Staples et al., 1983), or as a general effect throughout both uterine horns, as reported to occur in the bovine uterus from day 19 to day 27 of pregnancy (Vander Wielen and King, 1984). Nothing is known about changes in specific lymphocyte subpopulations in the endometrium associated with attachment of the conceptus. It is possible that only certain types of lymphocyte undergo a reduction in number and that some subpopulations become activated as a result of attachment. Study of regulation of endometrial lymphocytes at this stage of pregnancy, which ensues coincident with production of interferon- $\tau$ (IFN- $\tau$ ), is warranted because IFN- $\tau$ can regulate lymphocyte function (Newton et al., 1989; Tuo et al., 1993) and products of lymphocytes such as granulocytemacrophage colony-stimulating factor-1 (GM-CSF) have the potential for altering conceptus function (Imakawa et al., 1993).

Once placentation is complete, there are few lymphocytes in the placentomal regions of the endometrium in sheep (Gogolin-Ewens et al., 1989) and cattle (Low et al., 1990). As pregnancy progresses, there is also a decrease in numbers of lymphocytes in the glandular epithelium (especially non-granulated lymphocytes) and stromal areas (especially MHC class $\mathrm{II}^{+}$cells and $\mathrm{T}^{+} 9^{+}$cells) of the interplacentomal region of the sheep endometrium (Gogolin-Ewens ef al., I989; Lee et al., 1992). In contrast, the number of granulated lymphocytes in the luminal epithelium of the interplacentomal sheep endometrium increases markedly during late pregnancy, by which time they comprise an estimated 10\% of cells in the epithelium (Lee $e t$ al. 1992). The increase in the number of these cells is accompanied by a concomitant increase in the size and number of granules (Gogolin-Ewens et al., 1989; Lee et al., 1992; Meeusen et al., 1993) (Fig. 1). The granulated lymphocyte that is activated during pregnancy has been identified as the $\mathrm{CDS}^{+} \mathrm{CD}_{45 \mathrm{R}^{+}} \gamma \delta \mathrm{TCR}^{+}$lymphocyte subpopulation (Meeusen et al., 1993).

\section{Possible functions}

Plasma cells in stromal follicles are presumably responsible for most local immunoglobulin synthesis but functions of other endometrial lymphocyte populations are unclear. The CD8 ${ }^{+} \mathrm{CD} 45 \mathrm{R}^{-} \gamma \delta \mathrm{TCR}^{-}$ cell is presumably an $\alpha \beta \mathrm{TCR}^{+}$cell and may function like other $\mathrm{CD}^{-}{ }^{+}$lymphocytes in $\mathrm{MHC}$ class-I-restricted cytolysis of cells infected with viruses and protozoa. The remaining two subsets of lymphocytes in the endometrial epithelium both express CD45R antigen, which in peripheral blood reacts with B cells and a small fraction of circulating I cells (Mackay et al., 1987). Endometrial CD45R ${ }^{+}$ cells do not express B-cell markers and express certain T-cell markers weakly (CD8) or not at all (CD5) (Lee et al., 1988; Gogolin-Ewens et al., 1989; Meeusen et al., 1993). The high degree of granularity of the $\mathrm{CD}^{+}{ }^{+} \mathrm{CD} 45 \mathrm{R}^{+} \gamma \delta \mathrm{TCR}^{+}$lymphocyte population as well as the fact that they are apparently activated during late pregnancy has led to the speculation that one of their functions is to secrete cytokines that promote conceptus development (Meeusen et al., 1993). Another proposed function for lymphocytes of the $\gamma \delta$ TCR lineage include recognition of microbial antigens and tumour cells (Haas et al., 1993). Unlike T-cells of $\alpha \beta$ TCR lineage, $\gamma \delta \mathrm{TCR}^{+}$lineage do not readily recognize MHC antigens or participate in tissue rejection (Haas et al., 1993). Thus, these cells may not recognize conceptus alloantigens, There are also reports that $\gamma \delta \mathrm{TCR}^{+}$lymphocytes can downregulate immune responses (Howard et al., 1989). The function of the endometrial CD $45 \mathrm{R}^{+} \gamma \delta \mathrm{TCR}^{-}$cells is unknown; they could be analogous to the natural killer (NK) like cells reported in mice and humans (King and Loke, 1991), but there is no evidence for this. 


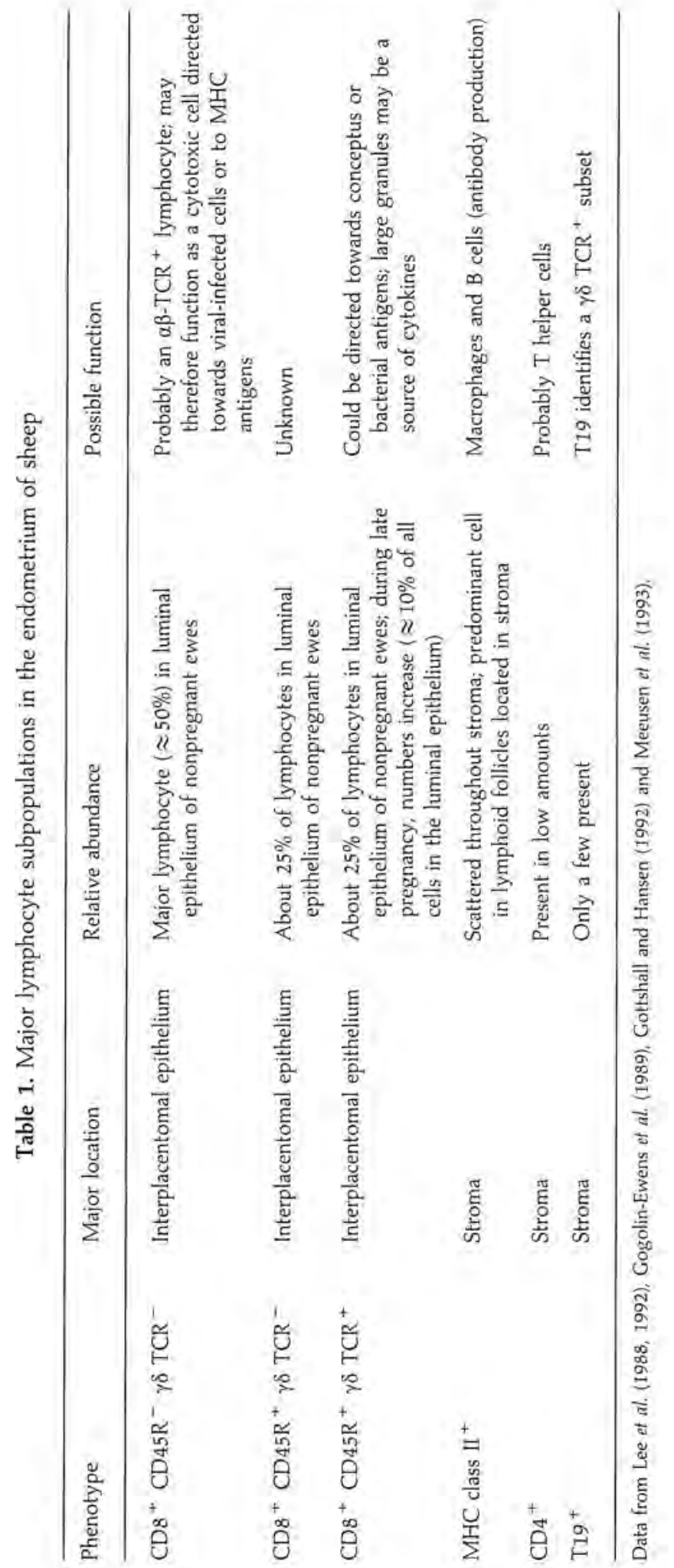



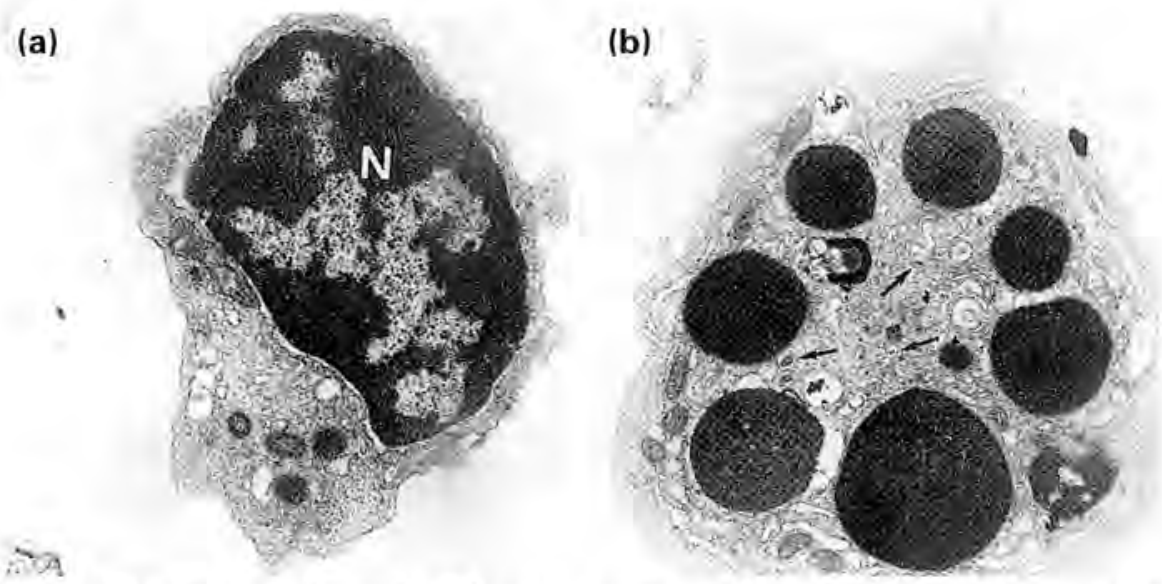

Fig. 1. Characteristics of granulated lymphocytes recovered from epithelium of ewes: (a) a granulated cell recovered from a nonpregnant uterus; and (b) a granulated cell recovered from the uterus of a pregnant ewe. Note the increase in number and size of granules associated with pregnancy. N: nucleus. The arrows in (b) represent small vesicles that are postulated to be involved in granule formation. Magnification: (a) $\times 10145$ (b) $\times 16286$. Reproduced with permission from the European Joumal of Immunology (Meeusen et al., 1993).

Natural killer cells could potentially be detrimental to the conceptus because lymphokine-activated killer cells can lyse peri-attachment sheep conceptuses (Segerson and Gunsett, 1994).

\section{Antigenicity of Spermatozoa and the Conceptus}

Spermatozoa can be antigenic in females (Menge, 1969; Awad et al., 1984; Lander et al., 1990), but there are only a few reports of antibody responses to spermatozoa associated with reduced fertility (Awad et al., 1984; Erski-Biljic and Varadin, 1985). Deposition of semen in the reproductive tract results in migration of leucocytes (primarily polymorphonuclear leucocytes) into the uterus (Mattner, 1968). Accordingly, many spermatozoa are probably lost by phagocytosis and not accessible to cellular components causing specific immunity. However, seminal components inhibiting phagocytosis of spermatozoa have been reported in cattle (Strzemienski, 1989). Specific immunity mediated by lymphocytes is probably also inhibited by an RNase and an antibacterial protein found in seminal plasma that inhibits T-and B-cell proliferative responses (Derwenskus et al., 1989). Immunization of heifers with spermatozoa up to 21 days after insemination was reported to cause early embryonic death (Menge, 1969). This finding suggests that embryos share antigens with spermatozoa and that embryonic loss could result from immunological recognition of these antigens. The study involved small numbers of animals and has implications important enough to warrant replication of the experiment.

The bovine blastocyst expresses paternally and maternally inherited polymorphic $\mathrm{MHC}$ class I antigens (Templeton et al., 1987). After placentation, the antigenicity of the placenta is diminished. In sheep, there was no detectable expression of MHC class I or class II antigens on fetal placental tissues in contact with endometrium (Gogolin-Ewens et al., 1989). In cows, placentomal chorion was also negative for $\mathrm{MHC}$ antigens (Low et al., 1990) but there was expression of MHC class I antigen on limited regions of the interplacentomal chorion. The antibody used by Low et al. (1990) recognizes a monomorphic determinant of MHC class I molecules and it is not certain whether molecules detected were polymorphic. In humans, MHC class I molecules are of a generally monomorphic class (Schmidt and Orr, 1993). In spite of the reduced antigenicity of the placenta, anti-fetal leucocyte antibodies can be defected in the blood of parous sheep (Ford and Elves, 1974; Stear and Spooner, 1983), cattle (Newman and Hines, 1980) and goats (van Dam et al., 1976), possibly because females become exposed to fetal cells during pregnancy or after parturition (Newman and Hines, 1980). Maternal responses to 


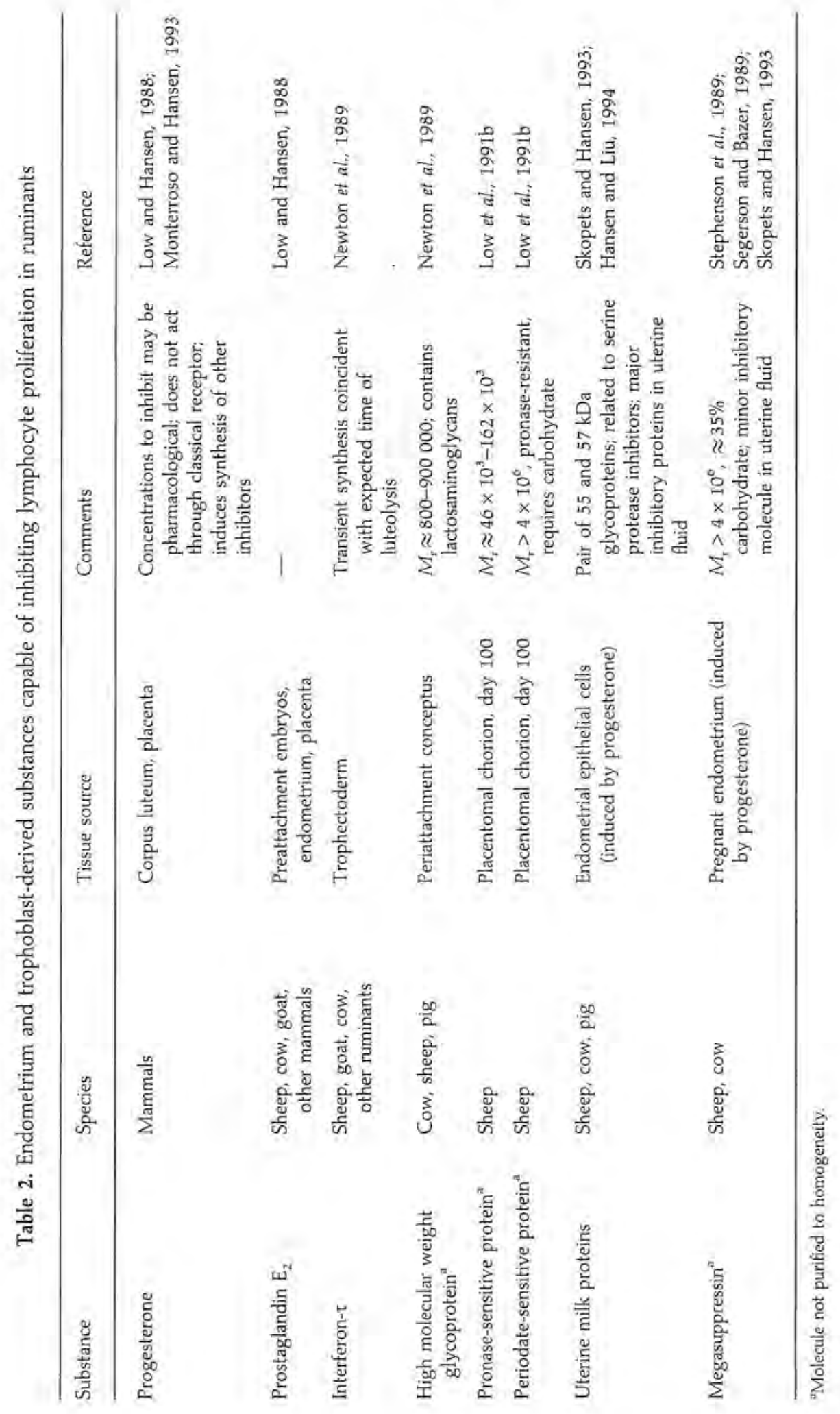


placental tissues may be beneficial to normal processes associated with parturition; it has been reported that cows that are MHC class-I-compatible with their fetuses have a higher rate of retained placenta (Joosten et al., 1991).

\section{Immunosuppression}

Although there is conflicting evidence (Rai-El-Balhaa et al., 1987), most of the evidence suggests that pregnant females do not experience systemic immunosuppression (Billingham and Lampkin, 1957; Outteridge and Dufty, 1973; Monterroso and Hansen, 1993). However, the conceptus-maternal interface is rich in molecules that can inhibit immune responses (Table 2) and the existence of so many locally produced lymphocyte-inhibitory molecules support Billingham's hypothesis (1964) that the placenta itself is in an immunosuppressed environment. However, caution is necessary when interpreting this evidence. Most immunoregulatory molecules produced by the uterus or trophoblast have been identified on the basis of inhibition of peripheral blood lymphocyte proliferative responses induced by T-cell mitogens or mixed lymphocyte reactions. It is likely that some molecules inhibit activity of cultured lymphocytes through mechanisms that would not affect immune responses in vivo. Molecules might also exert more complex immunoregulation in vivo than indicated by lymphocyte proliferation tests. The uterine milk proteins (UTMP), for example, block T-cell proliferative responses in vitro (Skopets and Hansen, 1993) and antibody production in vivo (Skopets et al., in press) but stimulate phytohaemagglutinin (PHA)-stimulated delayed hypersensitivity reactions in skin (Skopets et al., 1995). Clearly, there is a need to evaluate the effects of putative immunosuppressants on endometrial lymphocytes and to determine whether immune responses in utero are actually suppressed during pregnancy.

\section{Role of Progesterone in Regulating Uterine Immune Function}

The best evidence for alteration of uterine immune responses during pregnancy is indirect and involves the actions of progesterone, one of the major pregnancy hormones. It has long been known that females treated with progesterone are more likely to develop infection after intrauterine inoculation of bacteria (Rowson et al., 1953). Some of this effect of progesterone may be related to uterine drainage or the function of phagocytic cells. However, long-term ( 60 day) treatment of ovariectomized ewes also results in a decline in numbers of $\mathrm{CD} 45 \mathrm{R}^{+}$lymphocytes and MHC class $\mathrm{II}^{+}$cells in the endometrium (Gottshall and Hansen, 1992) and increased survival of intrauterine skin grafts (Hansen et al., 1986). Progesterone can inhibit lymphocyte proliferation directly at concentrations of $10^{-6}$ to $10^{-5} \mathrm{~mol} \mathrm{I}^{-1}$ (Low and Hansen, 1988; Monterroso and Hansen, 1993). These concentrations are only approached in the utero-ovarian lymph ipsilateral to the corpus luteum (Staples et al., 1982) and perhaps in the placenta of species such as sheep and goats in which there is significant placental progesterone synthesis. It is likely that many inhibitory effects of progesterone on uterine immune function are mediated indirectly through induction of other immunoregulatory molecules. Treatment of animals with doses of progesterone too low to affect lymphocyte proliferation directly can induce the presence of molecules that inhibit Iymphocyte proliferation in vitro in uterine secretions of ovariectomized ewes (Hansen et al., 1986; Stephenson and Hansen, 1990) and cows (Lander Chacin et al., 1990). Uterine fluid from progesterone-treated ewes can also reduce antibody responses in vivo (Stephenson and Hansen, 1990).

\section{The Uterine Milk Proteins - Putative Mediators of Effects of Progesterone on Uterine Immune Function}

Uterine fluid from pregnant ewes and cows also inhibits lymphocytes (Segerson and Bazer, 1989; Stephenson et al., 1989). The molecules responsible for most of the non-dialysable lymphocyteinhibitory activity in uterine fluid from pregnant ewes are a pair of progesterone-induced proteins called the uterine milk proteins (Skopets and Hansen, 1993). The biochemical properties and endocrine regulation of the UTMP have been reviewed recently (Hansen and Liu, 1994). This pair of progesterone-induced, basic glycoproteins, having molecular weights of 55000 and 57000 , makes up the majority of protein in uterine fluids of pregnant and progesterone-treated ewes and they are present 


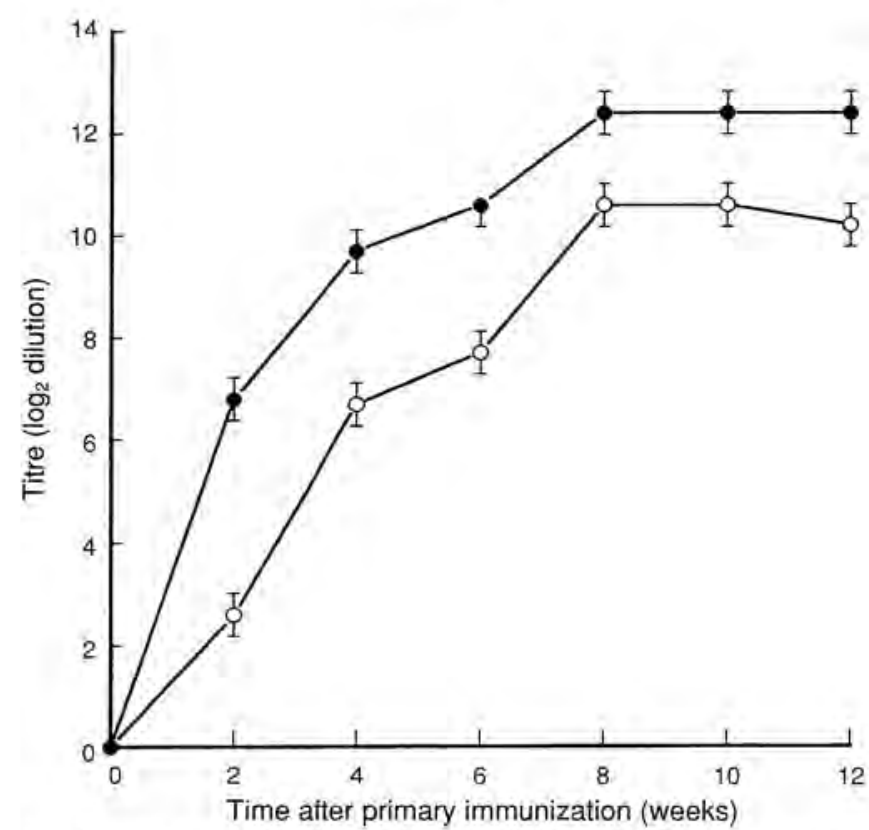

Fig. 2. Antibody titres in ewes immunized with ovalbumin that had been emulsified in adjuvant containing either ( ) uterine milk proteins (UTMP) or the negative control (D) ovine serum albumin (OSA). Note the reduced antibody response in ewes in which UTMP were co-administered; at 8 weeks, titres averaged 1:5404 for ewes receiving OSA and 1:1552 for ewes receiving UTMP. Reproduced with permission from American Journal of Reproductive Immunalogy (Skopets et al., in press).

in lower quantities within the bovine uterus. The two UTMP are related, having an identical amino-terminal amino acid sequence, and there is evidence that they are formed from a common precursor. The inferred amino acid sequence of UTMP indicates that the proteins are members of the serpin superfamily of serine protease inhibitors (Ing and Roberts, 1989). Although no antiprotease activity characteristic of serpins has been described for the proteins, the UTMP share two properties with another serpin, $\alpha 1$-antitrypsin, namely the ability to bind selectively to $\operatorname{IgA}$ (Hansen and Newton, 1988) and inhibit tymphocyte blastogenic responses (Skopets and Hansen, 1993).

The uterine milk proteins can inhibit proliferation of cultured peripheral blood lymphocytes induced by several T-cell activators including phytohaemagglutinin, concanavalin $\mathrm{A}$, mixed lymphocyte reactions and Candida albicans antigen (Skopets and Hansen, 1993; Skopets et al., in press). The concentrations of UTMP required to inhibit lymphocyte proliferation (about $50-500 \mu \mathrm{g} \mathrm{ml}^{-1}$ ) are high but well within the range of concentrations present in uterine fluid after about day 30 of pregnancy. The UTMP can also inhibit immune responses of the whole animal including antibody production in sheep (Fig. 2; Skopets et al, in press), NK cell activity (Liu and Hansen, 1993) and NK-cell mediated abortion in mice (Liu and Hansen, 1993). However, not all lymphocyte subpopulations are inhibited by UTMP. Skopets and Hansen (1993) reported that UTMP did not inhibit proliferation of sheep peripheral blood lymphocytes stimulated with the T- and B-cell activator pokeweed mitogen. UTMP also enhanced delayed hypersensitivity responses to subcutaneous administration of PHA (Skopets et al., in press). The selectiveness of actions of UTMP make it important to test whether UTMP can inhibit the action of endometrial lymphocytes before the significance of the proteins can be established.

The mechanism by which UTMP inhibits lymphocyte proliferation is incompletely understood. One possible mechanism could involve inhibition of proteases such as dipeptidyl peptidase IV involved in lymphocyte activation. However, UTMP do not block dipeptidyl peptidase IV coactivation of 
lymphocytes or enzyme activity (Liu and Hansen, in press). One of the properties of serpins is their propensity to interact with other proteins and it is possible that UTMP bind to a cell surface receptor or soluble product of activated lymphocytes that are required for proliferation.

\section{Involvement of Cytokines in Regulation of Endometrial and Placental Function}

Many of the cytokines that were described originally as being products of the immune system have since been shown to play important roles as autocrine and paracrine regulators in many tissues including the reproductive tract. In rodents, several cytokines have been implicated in reproductive processes and the greatest evidence is for colony-stimulating factor-1 (Pollard et al., 1991), leukaemia inhibitory factor (Stewart et al, 1992), and interleukin I (Simón et al., 1994). A summary of cytokines that have been associaled with pregnancy in ruminants is presented in Table 3. Of these cytokines, IFN- $\tau$ is the only one for which an important role in pregnancy (regulation of luteal lifespan) has been established (Roberts et al., I992). Interferon- $\tau$ is a pleiotrophic molecule and, like other interferons, has antiviral (Pontzer et al, 1988) and immunosuppressive activity (Newton et al, 1989), induces synthesis of $2^{\prime}, 5^{\prime}$-oligoadenylate synthetase (Short ef al., 1991) and activates NK cells (Tuo et al., 1993). It is not known to what extent these other actions of IFN- $\tau$ are important to the course of pregnancy. Perhaps the decrease in the number of intraepithelial lymphocytes that occurs following IFN- $\tau$ secretion (Staples et al., 1983; Vander Wielen and King, 1984) is a result of immunoregulatory actions of IFN- $\tau$. The antiproliferative actions of interferons could also alter endometrial function, but recent experiments indicate that endometrial cell growth is only slightly affected by IFN- $\tau$ (Davidson et al., 1994).

Other cytokines may also play a role in pregnancy; GM-CSF has been localized to glandular epithelial cells of the ovine endometrium and it has been reported that it enhances IFN- $\tau$ synthesis by the ovine conceptus (Imakawa et al., 1993). In cattle, interleukin 1 has been detected in uterine flushings. It increases endometrial secretion of prostaglandins and inhibits growth of endometrial stromal cells (Davidson, 1994). In addition, leukaemia inhibitory factor (LIF) has been immunolocalized to stroma and epithelium of ovine endometrium (Vogiagis et al., 1994) and receptors for colony-stimulating factor 1 have been identified on bovine trophoblast (Beauchamp and Croy, 1991). Knowledge of the roles of these and other cytokines in pregnancy is incomplete because it is not known which cytokines are present in the ruminant reproductive tract, how their secretion is regulated, and whether the functions exerted by the cytokines are of critical importance to pregnancy. One major question is the degree to which cytokines at the conceptus-maternal interface are derived from cells of the immune system. According to Wegmann's immunotrophism hypothesis (1988), stimulation of lymphocytes by conceptus antigens should increase the cytokines available at the conceptus-maternal interface and promote conceptus growth and endocrine function. Consistent with this theory is the observation that bovine placental cells are sensitive to growth promoting effects of supernatants from activaled lymphocytes (Low et al, 1991a). However, the fact that the fetal placenta has reduced antigenicity and exists in an environment bathed in immunosuppressive substances makes the development of strong immune responses towards the conceptus unlikely. Cytokine secretion from endometrial leucocytes has not been described in ruminants, although granulated lymphocytes located in the endometrial epithelium of sheep are a potential source of lymphocyte-derived cytokines (Meeusen et al., 1993). Immune cytokines, identified in the ruminant uterus, that have a known origin are produced by trophoblast or endometrial epithelial cells (Table 3). Thus, it is possible that the major source of immune cytokines at the conceptus-maternal interface are these tissues rather than leucocytes. Cytokines from these sources could affect the function of both the conceptus and endometrial leucocytes.

\section{Conclusions: A Model of Conceptus-Immune Interactions}

On the basis of results presented in this paper, a model of conceptus-immune interactions in ruminants can be developed (Fig. 3). After early pregnancy, the placenta of the ruminant conceptus is of limited antigenicity, and expression of MHC antigens is absent or greatly reduced. Moreover, unlike most grafts, the contact between conceptus and the maternal system is limited to the outer layers of trophoblast and endometrium. Thus, lymphocyte trafficking into more antigenic regions of the 


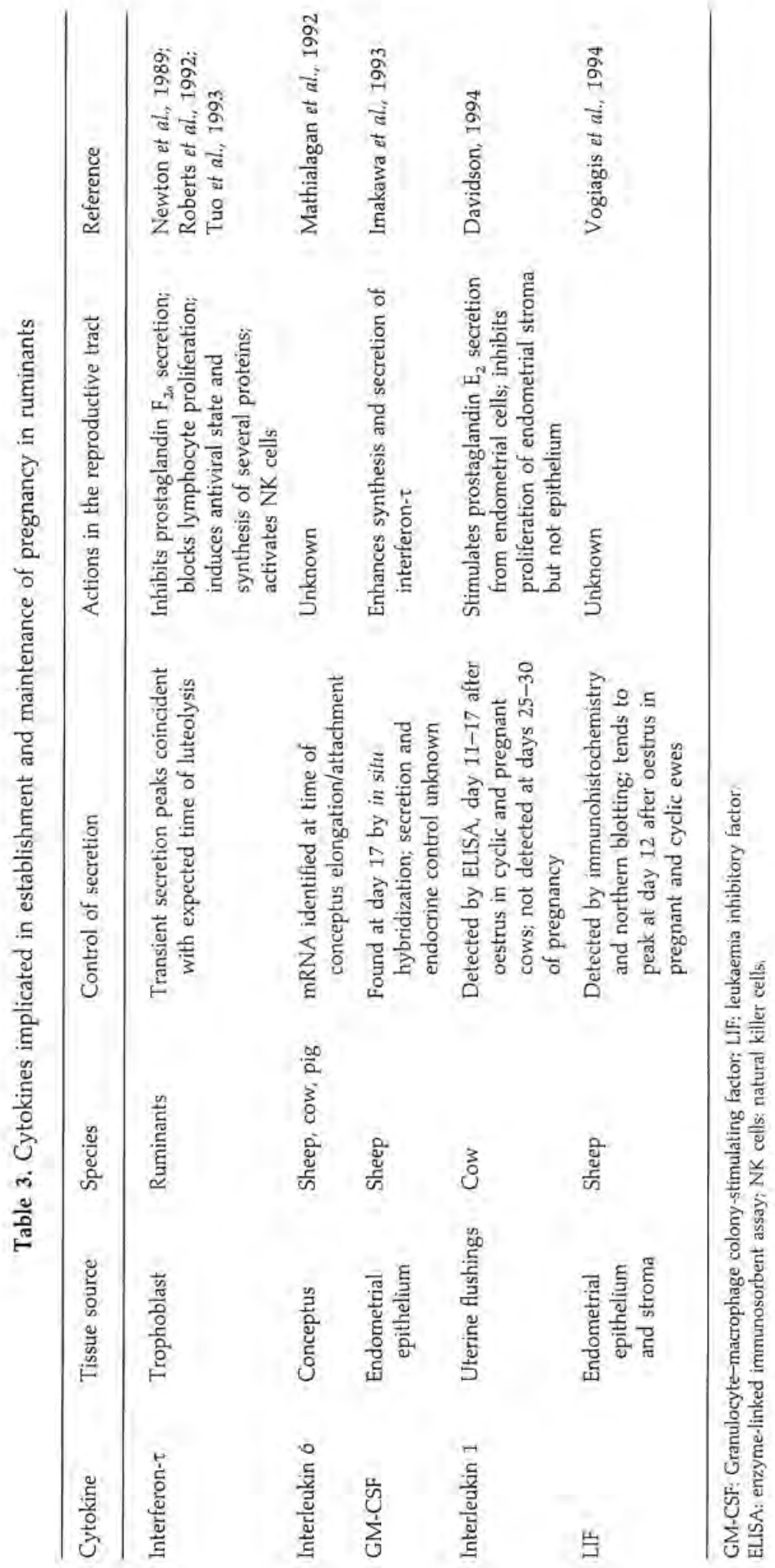




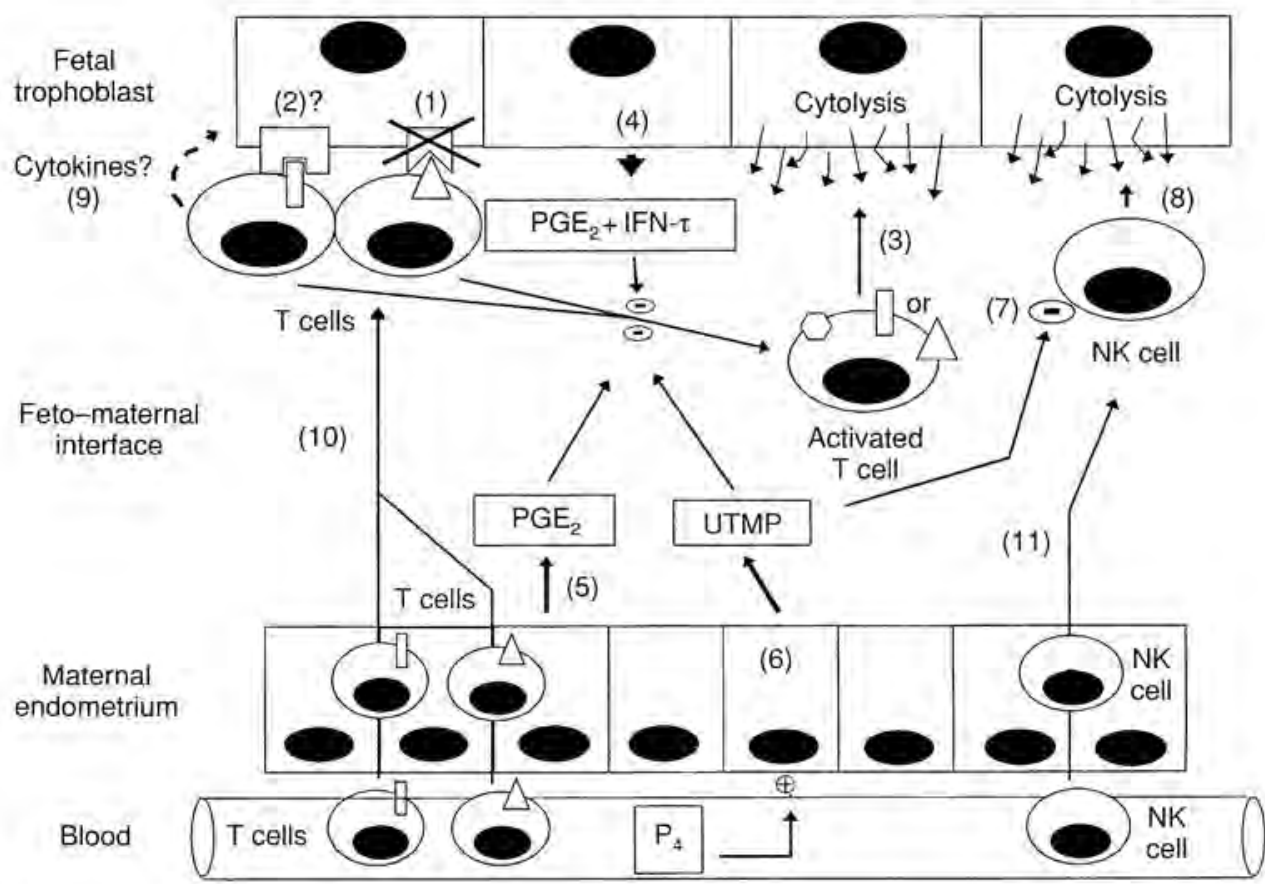

Fig. 3. Model of conceptus-immune interactions in ruminants. After early pregnancy, the trophoblast is of limited antigenicity, with expression of major histocompatibility antigens $(\varpi)$ being absent or greatly reduced (1). Thus, $T$ cells expressing the $\alpha \beta$ T-cell receptor $(T C R)(\Delta)$ are unlikely to recognize trophoblast as foreign. In addition, many of the lymphocytes present in the endometrium are $\gamma \delta \mathrm{TCR}^{+}$ lymphocytes ( $\square$ ) which probably have only limited ability to recognize MHC antigens. It is not known whether antigen-presenting molecules for these cells (河) are present on the trophoblast (2). Activation of anti-conceptus lymphocytes (indicated schematically by acquisition of interleukin-2 receptor $(0)$ ) could lead to cytolytic responses towards the trophoblast (3; cytolysis indicated by streams of arrows from the trophoblast cell) but these responses are probably blocked by molecules that can inhibit lymphocyte transformation. The most well-characterized of these are prostaglandin $\mathrm{E}_{2}\left(\mathrm{PGE}_{2}\right)$ from placental and endometrial tissues $(4,5)$, interferon- $\tau$ (IFN- $\tau$ ) from the trophoblast (4), and the progesterone-induced uterine milk proteins (UTMP) (6). The uterine milk proteins can also inhibit natural killer (NK) cells (7). This may be important because activated killer cells can lyse trophoblast (8). It is not known whether leucocytes in the uterus produce cytokines beneficial to the developing conceptus, but one possible source of these cytokines are the granulated CD45R ${ }^{+} \gamma \delta \mathrm{TCR}^{+}$ lymphocytes that increase in number and granularity in the luminal epithelium of the late-pregnant ewe (9). Note that while the source of endometrial lymphocytes is indicated as the blood (10), this has not been established. Similarly, the presence and source of NK cells in the endometrium of ruminants is conjectural (11). $\mathrm{P}_{4}$ : progesterone

conceptus is blocked. In addition, many of the lymphocytes present in the endometrium are $\gamma \delta \mathrm{TCR}^{+}$ lymphocytes that probably have only limited ability to recognize $\mathrm{MHC}$ antigens. Activation of anti-conceptus immune responses leading to cytolytic responses towards the trophoblast is further limited by the presence of molecules that can inhibit lymphocyte transformation. The most wellcharacterized of these are $\mathrm{PGE}_{2}$ from placental and endometrial tissues, IFN- $\tau$ from the trophoblast during early pregnancy, and the UTMP. Progesterone plays a central role in inhibition of immune responses in actions that are mediated through endometrial secretion of UTMP but which could also include other unknown effects.

The possibility that leucocytes in the uterus produce cytokines beneficial to the developing conceptus is a largely untested hypothesis in ruminants. One possible source of these cytokines is the granulated lymphocytes that increase in number and granularity in the luminal epithelium of the ewe at 
late pregnancy. This increase in number and activity suggests that these cells are largely unresponsive to the inhibitory effects of the many lymphocyte-inhibitory molecules present at the conceptus-maternal interface. Production of cytokines by these lymphocytes, or by tissues such as endometrium and trophoblast, may be important for regulating growth, gene expression and hormonal secretion of placental, fetal and endometrial tissues.

Our understanding of conceptus-immune interactions in ruminants is fragmentary. This is mainly because little is known of the functions of endometrial lymphocytes with respect to activation status, responsiveness to putative immunoregulatory molecules and production of cytokines. Elucidation of the functions of these cells should clarify their role in the uterus, while simultaneously providing a more complex view of the cellular interactions between placenta and the diverse cellular populations in the endometrium that are required for a successful pregnancy.

This is Journal Series Number R-04068 of the Florida Agricultural Experiment Station. The author gratefully recognizes the students, postdoctoral scientists and visiting scholars who contributed to the work from his laboratory that was reported in this paper as well as the sponsors of the research: NIH (Grant HD 2067I and HD 26421), USDA (Grant 89-37240), the Florida Dairy Milk Checkoff Program and CIBA-GEIGY. Appreciation is also extended to $\mathrm{M}$. J. Fields, for providing the author with the collection of early papers in the field compiled by $\mathrm{A}$. C. Warnick, and to W. W. Thatcher, for providing a thorough review of the paper.

\section{References}

Awad HH, El Ghannam FH, El-Sawaf SA and Eidroos A (1984) Immunological studies on the cervical mucus of the normal and repeat breeder cows and buffaloes and its relation to the problem of infertility. Proceedings of The 10th International Congress on Animal Reproduction and Artificial Insemunation (Champaign-Urbana) 3.443

Beauchamp JL and Croy BA (1991) Assessment of expression of the receptor for colony-stimulating factor- 1 ( $\mathrm{fms}$ ) in bovine trophoblasts Biology of Reproduction 45 311-817

Billingham RE (1964) Transplantation immunity and the maternal-fetal relation. New Englund Joumal of Medicine $270667-775$

Billingham RE and Lampkin GH (1957) Further studies on tissue homotransplantation in cattle Journal of Embryology and Experimental Morphology 5 351-367

Croy BA and Chapeau C (1990) Evaluation of the pregnancy immunotrophism hypothesis by assessment of the reproductive performance of young adult mice of genotype scid/ scid.bg/bg Joumal of Reproduction and Fertility 88 231-239

Curtain CS, Clark BL and Dufty JH (1971) The origins of the immunoglobulins in the mucous secretions of cattle Clinical and Experimental Inmunology 8 335-344

Davidson JA (1994) Regulation of Boome Uterine and Embryonic Function by interleukin-1 and Interferons. MS Thesis, University of Florida, Gainesville, FL

Davidson JA, Betts JG, Tiemann U, Karnwanja L.A, Monterroso VH and Hansen PJ (1994) Effects of interferon- $\tau$ and interferon- $\alpha$ on proliferation of bovine endometrial cells Biology of Reproduction 51 700-705

Derwenskus KH, Sprinzl M and Scheit KH (1989) Inhibition of cell proliferation by basic proteins from bull seminal plasma Biological Chemistry Hoppe-Seyler $370284-292$

Erski-Biljic M and Varadin M (1985) Significance of immunologic sterility in farm breeding of dairy cattle American Journal of Reproductive Immunology and Microbiology 772 (Abstract)

Ford CHJ and Elves MW (1974) The production of cytotoxic antileucocyte antibodies by parous sheep Jotirwal of imntunogenetics 1 259-264
Gogolin-Ewens KJ, Lee CS, Mercer WR and Brandon MR (1989) Site-directed differences in the immune response to the fetus immunology 66 312-317

Gottshall SL and Hansen PJ (1992) Regulation of leucocyte subpopulations in the sheep endometrium by progesterone Immunology 76 636-64I

Haas W, Pereira P and Toneqawa S (1993) Gamma/delta cells Annual Review of immunology $11637-685$

Hansen PJ and Liu W-J (1994) Biochemical/physiological properties of endometrial serpin-like proteins Advances in Contraceptive Delivery Systems 10 $339-354$

Hansen PJ and Newton GR (1988) Binding of immunoglobulins to the major progesterone-induced proteins of the sheep uterus Archives of Biochemistry and Biophysics 260 208-217

Hansen PJ. Bazer FW and Segerson EC (1986) Skin graft survival in the uterine lumen of ewes treated with progesterone American Joumal of Reproductive Immunology and Microbiology $1248-54$

Howard CJ, Sopp P, Parsons KR and Finch J (1989) In vivo depletion of BoT4 (CD4) and of non-T4//T8 lymphocyte subsets in cattle with monoclonal antibodies Ewropean Joumal of Immunology 19 757-764

Imakawa K, Helmer SD, Nephew KP, Meka CS and Christenson RK (1993) A novel role for GM-CSF: enhancement of pregnancy specific interferon, ovine trophoblast protein-1 Endocrinology $1321869-1871$

Ing NH and Roberts RM (1989) The major progesteronemodulated proteins secreted into the sheep uterus are members of the serpin superfamily of serine protease inhibitors Journal of Biological Chemistry 264 3372-3379

Joosten I, Sanders MF and Hensen EJ (1991) Involvement of major histocompatibility complex class 1 compatibility between dam and calf in the aetiology of bovine retained placenta Animal Genetics 22 455-463

King A and Loke YW (1991) On the nature and function of human uterine granular lymphocytes Immunology Today 12 $432-436$ 
Lander MF, Hansen PJ and Drost M (1990) Antisperm antibodies in cows after subcutaneous and intrauterine immunisation Veterinary Record 126 461-462

Lander Chacin MF, Hansen PJ and Drost M (1990) Effects of stage of the estrous cycle and steroid treatment on uterine immunoglobulin content and polymorphonuclear leukocytes in cattle Theriogenology 34 1169-1184

Lee CS, Gogolin-Ewens K and Brandon MR (1988) Identification of a unique lymphocyte subpopulation in the sheep uterus Immunology 63 157-164

Lee CS, Meeusen E, Gogolin-Ewens K and Brandon MR (1992) Quantitative and qualitative changes in the intraepithelial lymphocyte population in the uterus of nonpregnant and pregnant sheep American Journal of Reproductive Immunology $2890-96$

Liu W-J and Hansen PJ (1993) Effect of the progesteroneinduced serpin-like proteins of the sheep endometrium on natural-killer cell activity in sheep and mice Biology of Reproduction 49 1008-1014

Liu W-J and Hansen PJ Progesterone-induced secretion of dipeptidyl peptidase IV (cluster differentiation antigen-26) by the uterine endometrium of the ewe and cow that costimulates lymphocyte proliferation Endocrinology 136 in press

Low BG and Hansen PJ (1988) Immunosuppressive actions of steroids and prostaglandins secreted by the placenta and uterus of the cow and sheep American Joumal of Reproductive Immunology and Microbiology 18 71-75

Low BG, Hansen PJ, Drost M and Gogolin-Ewens KJ (1990) Expression of major histocompatibility complex antigens on the bovine placenta Journal of Reproduction and Fertility $90235-243$

Low BG, Hansen PJ and Drost M (1991a) Stimulation of proliferation of bovine placental cells by products of activated mononuclear leukocytes In Vitro Cellular and Developmental Biology 27A 639-645

Low BG, Hansen PJ and Drost M (1991b) Inhibition of Iymphocyte proliferation by ovine placenta-conditioned culture medium Journal of Reproductive Immunology 19 25-41

Mackay CR, Maddox JF and Brandon MR (1987) A monoclonal antibody to the 2220 component of sheep LCA identifies B cells and a unique lymphocyte subset Cellular Immonology $11046-55$

Mathialagan N, Bixby JA and Roberts RM (1992) Expression of interleukin- 6 in porcine, ovine and bovine periimplantation conceptuses Molecular Reproduction and Development 32 $324-340$

Mattner PE (1968) The distribution of spermatozoa and leucocytes in the female genital tract in goats and cattle fournal of Reproduction and Fertility 17 253-261

Medawar PB (1953) Some immunological and endocrinological problems raised by the evolution of viviparity in vertebrates Symposia of the Sociefy for Experimental Biology 7 320-338

Meeusen E, Fox A, Brandon M and Lee CS (1993) Activation of uterine intraepithelial $\gamma \delta$ I cell receptor-positive lymphocytes during pregnancy European Joumal of Inmunology 23 1112-1117

Menge AC (1969) Early embryo mortality in heifers isoimmunized with semen and conceptus Jourtual of Reproduction and Fertility 18 67-74

Monterroso VH and Hansen PJ (1993) Regulation of bovine and ovine lymphocyte proliferation by progesterone: modulation by steroid receptor antagonists and physiological status Acta Endocrinologica 129 532-535
Newman MJ and Hines HC (1980) Stimulation of maternal anti-lymphocyte antibodies by first gestation bovine fetuses Joumal of Reproduction and Fertility 60 237-241

Newton GR, Vallet JL, Hansen PJ and Bazer FW (1989) Inhibition of lymphocyte proliferation by ovine trophoblast protein-I and a high-molecular-weight glycoprotein produced by the peri-implantation sheep conceptus American Joumal of Reprodictive Immunology and Microbiology 19 99-107

Outteridge PM and Dufty JH (1973) The immune response of cattle during pregnancy and early lactation Research in Veterinary Science 14 389-391

Pollard JW, Hunt JW, Wiktor-Jedrzejczak W and Stanley ER (1991) A pregnancy defect in the osteopetrotic (op/op) mouse demonstrates the requirement for CSF-1 in female fertility Developmental Biology 148 27.3-283

Pontzer CH, Torres BZ, Vallet JL, Bazer FW and Johnson HM (1988) Antiviral activity of the pregnancy recognition hormone ovine trophoblast protein-1 Biochemical and Biophysical Research Communications 152 80I-807

Rai-El-Balhaa G, Abdullah A, Pellerin Jt, Thibaud D and Bodin G (1987) Blastogenic response of peripheral blood lymphocytes from multiparous pregnant ewes American Joumal of Reproductive Immunology and Microbiology 14 110-1I4

Roberts RM, Leaman DW and Cross JC (1992) Role of interferons in matemal recognition of pregnancy in ruminants Proceedings of the Society for Experimental Biology and Medicine 200 7-18

Rowson LEA, Lamming GE and Fry RM (1953) The relationship between ovarian hormones and uterine infection Veterinary Record 22 335-340

Schmidt CM and Orr HT (1993) Maternal/Fetal interactions: the role of the MHC class I molecule HLA-G Critical Reviews in Inmunology 13 207-224

Segerson EC and Bazer FW (1989) High molecular weight basic and acidic immunosuppressive protein components in uterine secretions of pregnant cows Biology of Reproduction 41 1014-1023

Segerson EC and Gunsett FC (1994) In vitro and in vioo effects of lymphokine-activated killer cells upon preattachment ovine conceptuses Joumal of Immunology 152 2938-2951

Short EC, Geisert RD, Helmer SD, Zavy MT and Fulton RW (1991) Expression of antiviral activity and induction of $2^{\prime}, 5^{\prime}$-oligoadenylate synthetase by conceptus secretory proteins enriched in bovine trophoblast protein-1 Biology of Reproduction 44.26I-208

Simón C, Frances A, Piquette GN, Danasouri IE, Zurawski G, Dang W and Polan M (1994) Embryonic implantation in mice is blocked by interleukin- 1 receptor antagonist Endocrinology 134 521-528

Skopets B and Hansen PJ (I993) Identification of the predominant proteins in uterine fluids of unilaterally pregnant ewes that inhibit lymphocyte proliferation Biology of Reproduction 49 997-1007

Skopets B, Liu W-J and Hansen PJ Elfects of endometrial serpinlike proteins on immune responses in sheep American Jounal of Reproductive Immunology 33 (in press)

Staples LD, Fleet IR and Heap RB (1982) Anatomy of the utero-ovarian lymphatic network and the composition of afferent lymph in relation to the establishment of preg. nancy in the sheep and goat Journal of Reproduction and Fertility 64 409-420

Staples LD, Heap RB, Wooding FBP and King GJ (1983) Migration of leukocytes into the uterus after acute removal of 
ovarian progesterone during early pregnancy Placenta 4 $339-350$

Stear MJ and Spooner RL (1983) Occurrence of cytotoxic lymphocyte antibodies in sheep. Research in Veterinary. Science 34 218-22.3

Stephenson DC and Hansen PJ (1990) Induction by progesterone of immunosuppressive activity in uterine secretions of ovariéctomized ewes Endocrinology 126 3168-3178

Stephenson DC, Hansen PJ, Newton GR, Bazer FW and Low BG (1989) Inhibition of lymphocyte proliferation by uterine fluid from the pregnant ewe Biology of Reproduction 41 1063-1075

Stewart CL, Kaspar P, Brunet LJ, Bhatt H, Gadi I, Kontgen F and Abbondonzo SJ (1992) Blastocyst implantation depends on maternal expression of leukaemia inhibitory factor Nature 359 $76-79$

Strzemienski PJ (1989) Effect of bovine serninal plasma on neutrophil phagocytosis of bull spermatozoa Joumal of Reproduction and Fertility 87 519-528

Templeton JW, Tipton RC, Garber T, Bondioli K and Kraemer DC (1987) Expression and genetic segregation of parental BoLa serotypes in bovine embryos Animal Genetics 18 $317-322$
Tuo W, Ott TL and Bazer FW (1993) Natural killer cell activity of lymphocytes exposed to ovine, type I, trophoblast interferon American Joumal of Reproductive Immunology 29 26-34

van Dam RH, Borst van Werkhoven C, van der Donk JA and Goudswaard J (1976) The production and evaluation of allo-antibodies for GL-A typing in goats Joumal of Immunogenetics 3 237-244

Vander Wielen AL and King GJ (1984) Intraepithelial lymphocytes in the bovine uterus during the oestrous cycle and early gestation Journal of Reproduction and Fertility 70 $457-462$

Vogiagis D, Fry RC and Salamonsen LA (1994) Leukaemia inhibitory factor (LIF) in ovine endometrium during the oestrous cycle and early pregnancy Proceedings of the 26 th Annual Conference of the Australian Society for Reproductioe Biology 61

Watson ED, Diehl NK and Evans JF (1990) Antibody responses in the bovine genital tract to intrauterine infusion of Actinomyces pyogenes Research in Veferinany Science 48 70-75

Wegmann TG (1988) Matemal T cells promote placental growth and prevent spontaneous abortion Immuriology Letters $17 \quad 297-302$ 